\title{
On queerly reading canid tropes in Eben Venter's Wolf, Wolf
}

\author{
Wemar Strydom \\ Wemar Strydom lectures in Afrikaans at North-West University, Potchefstroom. \\ Email: wemar.strydom@nwu.ac.za
}

\section{On queerly reading canid tropes in Eben Venter's Wolf, Wolf}

The intertwined effect of loss of power on facets of masculinist identity (being a son, a lover, a citizen) and on categories of belonging (filial, intimate, national) is explored in Eben Venter's Wolf, Wolf (2013). As the protagonist tries to navigate the lived actuality of contemporary South African life, the experience of multiple loss(es) leads him to consider the possibility of alternative ways of navigating the 'in-between' spaces of family structures, intimate connection, and national belonging. Curiously, the presence of canid tropes and canid symbolism appear alongside considerations of belonging. This article explores a reading of the canid presence and how it can productively be read as external manifestations of affective states, notably desire, shame and exclusion. Venter's intentional blurring of boundaries (especially within homoerotic and homosocial bonds) between $\mathrm{dog} /$ wolf/jackal and man, citizen and immigrant, messy, carnal corporality and immaterial sterile cyberspace, queers the relationships presented in the narrative. The canid presence (an erotised wolfhound mask, farm dogs as machinic extensions of white masculinity, sustained ontological slippage between dogs and immigrants) acts as textual indicator that the protagonist finds himself situated outside heteronormative, filial and national categories. Keywords: canid tropes; citizenship; Eben Venter; queer relationality.

"The shadow of the man assumes an autonomous and unspecified animal existence." — Gilles Deleuze, "Body, Meat, and Spirit: Becoming Animal”

\section{Introduction}

Loss figures in myriad ways in Eben Venter's Wolf, Wolf (2013), and its effect on various categories of belonging (filial, intimate, national) is seen in how protagonist Matt Duiker's notions of being a son, a lover, and a citizen is refracted in

108 his orientation towards the various male figures in his life: Matt's father, dying of 
cancer and slowly losing his ability to interact with the outside world; Jack, his on-and-off lover, who loses his home and then becomes unemployed; and his employee, Emile, a Congolese refugee trying to make a living during particularly xenophobic times. Multiple losses of ability, power, relationality, employment and citizenship leads the protagonist to consider the possibility of alternative ways of navigating 'in-between' spaces of belonging. Interestingly, the presence of canid tropes (jackals, dogs, wolves) and canid symbolism (ruminations on the hunt, a wolf-like mask worn by Jack, a dog accompanying Emile everywhere) appear alongside his considerations of belonging. In this article, I attempt a reading of the canid tropes and canid symbolism to surface zones of indiscernibility between human and non-human animals. I am interested in how Matt's orientation toward the father, Jack and Emile-the archetypical patriarch, the lover, the other-can be read metonymically to represent shame, desire and exclusion, as well as how the canid figures of wolf and jackal and dog can be read as external realisations of these inner states.

In the eyes of the patriarch, his son's desires for another man, and that which happens between the "debauched sheets" (173) of his son's bed, comes to constitute, for him, his son's being; for the father, the function of male-ness (which in the novel is two-fold: to operate sexually in producing an heir, and to produce in the more general capitalist sense of the word) comes to outweigh the essence of a person's being. The restrictive nature issued from the father's insistence on the son 'carrying on the line' crystallises in a sense of dutiful progeny (often a primary driver of Venter's protagonists) and considerations of such a duty permeate the first parts of the novel: Matt is the "only, the first-born, the son [...] he's the one who'll be able to take it further" (106). When the son goes against the father's wishes and allows Jack entry into his father's house, it results in a different kind of non-continuation: non-inheritance. (The son refusing the transfer of line; the father in return denying transfer of inheritance.)

Significantly, Jack is allowed entry into the patriarchal space only whilst wearing a wolf-hound mask, creating a queerly human-animal persona he playfully calls 'Wolfie. The introduction of Wolfie shows how the notion of a gay son being tasked with continuing the progeny, carrying the fatherly seed, queers this specific (male) role. By its very refusal, it replaces or recodes progenitory duty with an emphasis on different ways of connecting and belonging. Venter's intentional positing of the wolf persona as sexualised affront to the patriarchal culminate in Matt and Jack's decision to go live on Rondebosch Common. This decision is fuelled by their indignation at the non-inheritance, and at the subsequent forced selling of the family home (an un-domestication of sorts).

On the Common, they themselves start to resemble the dogs around them (239). At the same time, they start terrorising the new owners of the father's house, 
On queerly reading canid tropes in Eben Venter's Wolf, Wolf

the Mkhonza family, while wearing the same wolfhound mask Jack wore the fateful night he was invited into the patriarch's house. The hooliganism and decidedly anti-social behaviour seems puzzling to the first-time reader (and is not nearly as 'playful' as initial reviews of the novel make it out to be), as it appears to constitute a self-marginalisation through an acceptance of dog-like un-domestication. Their precarious situation is compounded by the fact that Matt then loses his livelihood (he bungles away his takeaway business due to sullen incompetence, and the business is later appropriated by Emile). In the last pages of the novel, Jack is killed, presumably by the new owners of the house, driven to desperation by the campaign of terror. His death is foreshadowed by a jackal hunt described earlier in the novel. The end of the novel thus constitutes a decentring of white male power, place and positionality, and continues the thread of fragile masculinity and the effect of brutal intimacy (23) exhibited by the men in Venter's novel.

As can be seen from the short narrative overview, male loss and the canid presence lie close together. The canid figures impact queerly on Matt's sense of belonging by destabilising certainties around normative sexual praxis and citizenship. Canid tropes usually stand in the frame of public relationality, i.e. our ability to form interactional identifications with(in) larger groups of people. Thus, the figure of the dog, in its traditional role of human companion and as a symbol for relational belonging, is modulated in Venter's text. Conversely, the figure of the wolf, in its specific guise in folklore, is also problematised: rather than the big, bad wolf of fairy tales, the sexualised persona of Wolfie can be read as a semiotic agitator, a queer persona that prods at the confines of heteronormative homosociality.

\section{Canid tropes and/as external manifestations of internal states}

Frida Beckman explicates differences between animals as ciphers and indices. On the one hand, there's the long-held use of nonhuman animals as functional, cipher-like "place fillers". On the other hand, as opposed to such "casual anthropomorphism" (132), animals can be used as indices, as when a particular animal is employed in the narrative "in a representational function [with] the specificities of indices important to the philosophical argument in which they appear" (133). Another use of the animal, beyond its status of mere 'place-filling' cipher or functional index, is as trope. Tropes are accompanied by literary baggage-the affective resonance we as readers bring to the text-which can be activated and/or subverted. For example, Venter, in a sense, reverse-engineers the wolf trope; Wolfie, far from resembling the dangerously beguiling lupine creatures of folkloric myth, is the only character who questions the ethical behaviour of those around him (Venter 239): When Jack is allowed to enter the ancestral home in a wolfhound

110 mask, the persona of Wolfie becomes not only a manifestation of the lover's illicit

Tydskrif vir Letterkunde 55.3 (2018) 
entry into the paternal and patriarchal space, but also of a queer challenge to the father's-and Afrikaans culture's-heteronormative demand for progeny.

What happens when canid tropes are used in such a specific manner, and when the reader considers these tropes' literary baggage alongside their function in the text? Venter's use of canid tropes-obedient dog and sexualised wolf and hunted jackal, with all the literary baggage these entail—can be explored in light of Gilles Deleuze's zones of indeterminacy and, specifically, as manifestations of shame, desire and exclusion. In "The Body, the Meat and the Spirit: Becoming-Animal" (1981), Deleuze discusses indeterminate zones-the in-between spaces created by experiences of loss-in the works of Francis Bacon. Describing Bacon's process of replacing human heads and faces with animal heads and faces, he writes:

What happens is that the man's head is replaced by an animal; but this is not the animal as form, it is the animal as outline [...]. What happens is that an animal, a real dog for example, is outlined as the shadow of its master; or conversely the shadow of the man assumes an autonomous and unspecified animal existence.

The shadow escapes from the body like an animal to which we give shelter. (44)

Deleuze sees such shadows of excess echo in the intense affective states represented in Bacon's work: we see shame as a scuttling dog; desire as a wolflike creature, baring its fangs. However, he warns against seeing a "formal correspondence" in this relation, and instead emphasises how "a zone of the indiscernible, of the undecidable between man and animal" is created (44). In the novel, instances of canid-related symbolism-such as the erotised wolfhound mask-are textual indicators that the protagonist finds himself situated outside and between humancentred, heteronormative and national categories. Indeed, intentional blurring of boundaries (especially within homoerotic and homosocial bonds) between dog/ wolf and man, between citizen and immigrant, between messy, carnal corporality and immaterial sterile cyberspace, is traceable throughout Venter's text.

When Deleuze writes of the "animal not as form, but as outline" and as "shadow escap[ing] from the body like an animal to which it gives shelter", he is approximating how zones of the indiscernible and undecidable 'discrete' units such as human and animal are created (44). External manifestations of inner states are the 'animal' to which the body 'gives shelter. These are given shape not in the canid figures themselves, but rather in the zones of interaction, of refraction opened up by the presence of these figures-if we actively read for these zones.

\section{The shadows of men: dogs and masculine inclusion}

Dogs figure in a number of passages on filial relations between men, especially passages that bring masculinity in relation to violence and subjugation, such as a lengthy description of a visit to the family farm where a jackal hunt is planned. Dogs act here as machinic extensions of the (white) men on the farm and are imbued with the men's contextually situated power, non-agential figures to exercise 
On queerly reading canid tropes in Eben Venter's Wolf, Wolf

control over and with which to violently subdue the other-cyphers of exclusion, thus. The farm space is one of an extreme marriage of the heteronormative and the homosocial; an all-male zone coded in violence and naturalised as instinctual. The hunt leads Matt to ponder the exclusionary and performative nature of such masculinity, and of his own role in a system of gendered praxis: "It's the exclusivity of the experience that he'd never be able to share in [...] the smell of gun oil, of dust and veld and a bit of blood, conspicuously macho: he doesn't cut it, he's not one of them" (Venter 135). In his focalisation, the heterosexual-homosocial is elevated to 'instinctual': "men come in, full of themselves-not with conceit, just full of the experience they share with each other as well as the [...] dogs, all of them waiting there down-wind in the veld with a cigarette and a swig from the hip flask, speech reduced to a single word, to breathing. [...] Now they're back with the experience" (134). This unspecified and nebulous instinctual sphere's impact is also seen on other characters on the farm, such as Uncle Hannes, whose relation to his dogs is coded as filial (he refers to his dogs as "my kroos").

The instinctual patriarchal and heteronormative homosocial space of the farm is mirrored in the father's house in the city. Specifically the father's study is seen as a non-connective space where, quite early in the narrative, the reader is made privy to the brutality of male intimacy (146) in the zonal interplay between hypermasculine father, homosocial space, and gay son. Matt recalls how, as a young boy, he was kept waiting to be allowed into his father's study, where his father and Uncle Diek (sic)

were regaling each other with lecherous tidbits, their ties loosened, sleeves rolled up over hairy forearms. [...] $\mathrm{Pa}[\ldots]$ cut short what he was saying and looked at his son. He could have said anything to him then. [...] But the words weren't spoken, he'll never know what it was. Only: he was not admitted to the circle. [...] His father wanted to admit him, wanted him to experience his palpable charm, his passion and perseverance and principles, everything that made up his manly ego, but, as with an animal, instinct warned him off: you're dealing with a different kind of creature here. It was all on his tongue, in his glance: his son, his own, his flesh and blood. How, dear Lord, had this come about? (10-1, emphasis added)

In Venter's novel, heteronormativity and heterosexism are not presented as natural, but rather as instinctual, and are specifically tied to the experience of certain spaces. This instinctual spacing is surfaced and challenged by the Wolfie persona's entrance. Suggestively, his entrance is coded in an erotic register that counters the way heteronormativity is posited as instinctual: "Jack goes down on all fours and trots on the spot. The cocked head looks at him with vibrating whiskers, and deep inside is the glint of real eyes. He announces that he's moving in as a dog, his name is Wolfie. Uncle Bennie won't mind, of course. Doesn't he have a soft spot for dogs?" (155). When the father enquires as to who is at the door, Matt's response is telling; instead of acknowledging the 'wolf' at the door, he simply states: "Scav-

Tydskrif vir Letterkunde 55.3 (2018) 
enging dogs or something, Pa. I think somebody further up in the street let their dogs out on their own to go and do their business" (158). The more erotic undertones of his answer shimmers through in the Afrikaans original's "losloperhonde" as well as the blurb's more erotic description: "The intimate space where Matt is waiting for his father to die is fatefully invaded by a wolf-like creature."

Wolfie-it can only ever be a diminutive form, within such brutal masculine frames-comes to constitute a possible break with instinctual patriarchy, as it shows duty to be imaginary, even when progenitory codes are so normalised in Afrikaans culture: "What would happen to the world if everybody was like you and your friend? Where would our children come from? [...] There will be no more progeny. The bloodline runs dry" (178). The father is shown to conflate species continuation with the continuation of self, allowing a reading in which the fear of his son as sexual other is shown to be partly a projection of his own fears about dying, about his own corporeal non-continuity, assuaged only by the (possible) continuation of his line, the survival of the instinctual.

\section{The shadows of (other) men: dogs and migrant exclusion}

Matt sees himself as standing 'outside' both the study and the hunt. This exclusionary worldview - with dogs as cyphers for a violent domestication of desiremanifests in Matt's heightened perception of Diamond, a 'fierce' (through Matt's focalisation) homeless dog who acts as avatar to the docile, stateless Emile. Matt's sense of shame at being less-than-a-man (within the homosocial confines of the narrative) drives his patronising and condescending behaviour towards the Congolese refugee-the only male occupying a lower social position than him in the narrative. Simultaneously, a creeping self-awareness of this behaviour manifests in how he becomes obsessively hyperaware of the out-of-place-ness of Diamond: He "goes out by the door, double-locks it, closes the steel door too, and pretends not to know that Emile is standing right there with the dog that is by now tugging hard at its chain" (149). The instinctual is imbued with a physicality, a 'sense of prickliness': "The short-arse won't leave. Behind his shoulder, on the pavement, the dog is huffing and puffing, slobber drooling from his gums. There's a slight prickliness between them, and Mattheüs inevitably reacts with caution. He wishes he would leave now" (149).

Matt's filial view of dogs means that he does not allow for the close attachment between Diamond and Emile, so he circumvents this by transposing the one for the other. Throughout, his focalisation sets up a metonymical relationship between the dog and Emile, as when Matt's focalisation blurs the object being addressed: "[t]he small guy's still there, squatting next to the rump of his dog, eyes fixed on him, unblinking" (150). As readers, we don't know whose eyes are referred to (Emile's or his dog's). As Matt's condescension grows, the zone between dog and immigrant becomes imbued with ontological slippage-with much more

Tydskrif vir Letterkunde 55.3 (2018) 
On queerly reading canid tropes in Eben Venter's Wolf, Wolf

than mere metonymy-and is blurred through the indiscernible in-between-ness of discourse relating migrants to dogs. This spills over the boundaries of the metonymical:

Emile is already taking the last mouthfuls of the food that he's just given him, sticks his tongue into the container, chucks container and spoon aside, the dog straining on its chain toward it all [...] the dog chomping at the plastic container, its head reaching almost to Emile's chest. Three, four times he looks around and grins toothily at Mattheüs, and he really does hope that it's nothing more than ordinary friendliness. (151)

The slippage comes uncomfortably close to raciality in the Afrikaans original, where Emile (or the dog-the reader themselves have to decide) "grinnik deur sy tande" (156). Of course, we read from personal assemblages to national categories of belonging. References to Diamond being tied up or being reprimanded oftentimes follow Matt's ruminations on national identity. The displacement of Matt's feelings of shame and inadequacy onto Emile manifests in the way his perception slips between Emile and Diamond, between immigrant other and non-human (animal) other.

It ultimately becomes apparent that Emile is not only more suited to dealing with the day-to-day challenges of living (a precarious life) in contemporary South Africa, but also much better equipped at running the takeaway business (having managed his own restaurant in Boma prior to fleeing to South Africa) than Matt himself-thus doubly challenging the sense of white male centrality Matt exhibits. Matt eventually asserts the only power left to him: firing Emile, and thereby dooming the Congolese's family to destitution. Emile's simple response of "Je te comprends" (149) (not 'I understand', but rather 'I understand you') is telling. ${ }^{1}$ Whilst spoken in a language Matt doesn't speak (does not have mastery over), he nonetheless understands the implication: "Mattheüs, in turn, understands exactly what he means. Emile implies that he understands everything, more than the takeaway he sees in front of him, whereas in fact there is nothing more to understand. And that's what Matteüs instinctively doesn't like" (149, emphasis added).

The reappearance of the instinctual is problematic here, as it activates correlate discourse on raciality and affective views on migrancy. In the protagonist's mind, dogs are ciphers to hunt with, to make obey, to violently subdue-domesticatethe other with. This worldview explains partly why Matt focalises Emile's dog, Diamond, in such a vicious manner. Whereas dogs are traditionally construed as faithful companions or guides, here Emile's dog come to encompass the apparent impenetrability and unknowing-ness of the Other, especially the immigrant other, through the externalised shame of the subject (of course within the specific actualities of a post-1994 South African reality). Venter's use of the 'faithful dog' literary trope goes beyond simply constituting an ontological relation between

114 Emile and Diamond. Zones of indiscernibility are activated so that Matt's sense

Tydskrif vir Letterkunde 55.3 (2018) 
of shame at the loss of (male) power is echoed in the presence of Diamond. After Matt fires Emile, he watches him walk away with his "back hunched like a dog cowering after a hiding" (247), thus tethering his description to larger discourses of referring to immigrants as dogs. (See, for example, Greta Olson on the ease with which we read animal-like characteristics onto/into migrant characters.)

\section{Reading tropes: kitchens and canids}

Reading Matt's displacement of masculinist inadequacy is a way of rediscovering "our everyday interactions with [animals] and the new spaces of possibility such interactions can create" (Kohn 4). Kohn's conceptualisation of an "ecology of selves" is useful here. Understanding that all beings participate in the world as "beings that have a point of view", allows for a reading of Diamond that "explode[s] [the] closed self-inferential circuit" (5) where the subject under discussion (dogs, for example) are made to be isomorphic with the discourse in which it is discussed (5). For example, if we read the trope so as to de-isomorph Diamond, we see that, from the dog's 'point of view', Matt is the antagonist. Reading in a de-isomorphic manner, we see that not all canid tropes in the novel have the same function or are activated on the same plane of signification: Diamond and Wolfie are different from both the farm dogs (as machinic extensions of Afrikaner violence and subjugation) and from the hunted jackal. While there are differences in the affective residue of each trope, both Wolfie and Diamond are orientated in relation to the father and to what the father represents. This positioning is clearly emblemised in two very similar scenes, both involving a canid figure in a kitchen, that bookend Matt's successive losses. The first details the presence of Wolfie in the domestic space of the father's house (Venter 176); the second shows how Diamond protects the counter of the takeaway shop when Emile, after he is fired by Matt, forcefully asserts ownership of the business (263). The similarities between the two scenes (with both, for example, particularising that only the ears of the canid figure are visible over a kitchen counter, perhaps signifying Matt's inability to comprehend completely) is more than just an interesting parallel; both are instances of the new (violently) invading the domestic 'space' of the status quo.

However, if the reader accepts Wolfie's/Jack's 'invasion', then must we not at the very least reconsider the validity of Emile's takeover of Matt's business? Both are instances of a 'rupture' or affront to (white) patriarchy, but only one-Jack's invasion of the patriarchal-is coded and focalised as positive, while the other-a (non-white) immigrant's takeover of a failing business-is presented as part of the breakdown of (white) socius. While there are salient differences between the two, both speak to manifestations of inner states, the coming to light of shame and desire, the externalisation (though not concretisation) of relations to others that make up our being-in-the-world. Even though Diamond is set up as the (troped)

Tydskrif vir Letterkunde 55.3 (2018) 
On queerly reading canid tropes in Eben Venter's Wolf, Wolf

conceptual opposite of Wolfie, I argue that they are equal in their relation or orientation toward the father, and that which the father represents. Thus, these two tropes have to be seen not in-and-of-themselves, but through their relation to Matt's being. For example, while Diamond is literally on a leash, metaphorically he can be read as standing for Matt's inability to let go of a past identity situated in power-over. Compared to this, the wolf motif in the novel is, though pervasive, at the same time a furtive presence. The wolf is an in-between entity to whom it becomes tricky to assign meaning, showing semiotic uncertainty in how the canid tropes are used (and are useful) within the semiotic sphere of the novel. While positing the entry of Wolfie as a challenge to such social expectations, to circumvent the direct imperative of the patriarch specifically in terms of the sexual life of the (only) son, the reader is affectively discouraged to read Diamond in the same manner. However, is Diamond not equally well-placed to challenge normative social expectations and circumvent the direct imperative of the patriarch? Why does only one type of subversion count? The novel, after all, charts positively the life of the son, incisively exploring the (re)configurations of desire and pleasure that can potentially disrupt historical and culturally-situated schemas of masculinities in South Africa (specifically in Afrikaner/Afrikaans culture). Could Diamond then not also be read more positively as a type of catalyst for an exploration of loss that sees the national and the intimate closely intertwined?

This discrepancy between how we read Wolfie positively, but Diamond negatively, speaks to the novel's overall attempt to universalise displacement in terms of (loss of) white male power. The novel's explicit mirroring of these two canid/ kitchen counter passages further speaks to the difference between power-to and power-over, as well as to how our perception (our reading) is grounded in our socio-cultural background. Reading these troped scenes together can be seen as a possible break with the reader's own filial, intimate, and national sense of belonging, senses which guide the process of finding resonance in alliance with particular characters within the narrative, at the cost of, perhaps, ignoring the potentiality of others. Questions arise: How do men (and also white men) navigate systems of oppressive patriarchy in order to create meaningful queer bonds? How does the reader's awareness of relationality affect how power is upheld? If even homosocial bonds serve to uphold "structures for maintaining and transmitting patriarchal power" (Sedgwick 25), then how do we get out of the bind where homosocial relations between men (and even desire between men) is seen as constitutive of this patriarchy? 
On queerly reading canid tropes in Eben Venter's Wolf, Wolf

\section{Reading tropes: resembling dogs}

The disruptive presence of a canid figure in a domestic space is inversely echoed in passages describing Matt and Jack's attempt to create a domestic-like living arrangement on the Common. This act of un-domestication is prompted after the ancestral home is sold to new owners. Matt and Jack squat illegally on Rondebosch Common, all their belongings crammed into a car. For some time, their life on the Common, and the car in which they live, resemble a "companiable chaos" (Venter 238). The novel sets up this episode as a concrete, messy, lived repudiation of the incorporeal spheres they previously moved in (Matt's porn addiction and Jack's overreliance on social media). The (concrete and very visible) wolfhound mask is "propped up against the windshield as a talisman" (238) and dog and wolf figures amalgamate: slowly, Matt and Jack's actions start resembling those of the dogs who are walked at the Common. For example, "[d]uring the night Matt goes outside with a roll of toilet paper to use the Common as the Common dogs do" (239) and Jack's students start complaining about his body odour (256).

I read the Rondebosch Common episode as a logical outcome of Wolfie's entrance into the patriarchal space, which surfaced the potential for new ways of being. The Wolfie persona introduces notes of erotic ferality into the (at that point) heavily heteronormatively coded domestic, thereby recoding possibilities of belonging. On the Common, this (temporarily) becomes an affirming way of connective intimacy, a companionable chaos that allows the lovers to traverse traditional and restrictive categories of sexual and national identity. On this, Jack Halberstam, who has been attempting to remodel the concept of 'wildness' as moral-aesthetic rupture, states that because queer "no longer signifies the wild array of embodiment and utopian projects it once did" (Gervasio), we should embrace "all that is chaotic, reckless, and intense to the point of violence" (Gervasio), leading to the taking up of a position that is against the self-interest of a rational citizen. For a while, the episode on the Common can be seen as an act of jouissance, a temporary revolution against the filial: Jack characterises the Common as a place of safety, a totalising space where differences-between possession and precarity, between human and animal-are upended temporarily: "Jack looks north, west, south, east. 'Nothing. You can't see anything of the city from here. Only the grass and the mountain there, to the west. This is our hiding place in the middle of the city. Isn't that something" (Venter 241). There is more to Jack's experience of the Common than simply seeing it as a space of security: Jack, who "knows the Common well" (237, in an apparent but veiled reference to cruising), describes it as a space where dogs run around freely, a space of "[p]ure joy. Up and down the paths among the grasses and flowers that have been trampled by people and by dogs' paws. He knows it sounds a bit silly, but he associates the Common with a zest for life" (237). Specifically, a scene (described through his focalisation) of two men (he is unsure if they are brothers or lovers) who often

Tydskrif vir Letterkunde 55.3 (2018) 
On queerly reading canid tropes in Eben Venter's Wolf, Wolf

walk their two chocolate-coloured Labradors, come to signify the exuberance of a life lived 'outside of' repressive power structures. The Common is simultaneously a 'hiding place' (241) and an onto-aesthetic experiment.

Matt and Jack's decision to resemble-dog can be read as an act of experimental ferality. And, since it is constructed on male intimacy, and in opposition to heteronormative capitalist structurings, then perhaps also as an act of feral masculinity. It is an intentional decision to un-domesticate, to disrupt expectations so as to create a space-ing of reflective being. Seeing Matt and Jack's choice as a temporal and ephemeral act of feral masculinity counters to a large extent the repressive and stratified filial relationality presented elsewhere in the novel. Through this, we may also read ferality in a slightly different manner: with an understanding that it connotes connection, instinctive cooperation and erotic kinship; a way of being definitely and defiantly at odds not only with the isolating individualism of the erotic and sexual self in late capitalism but also with heteronormative progenitory duty. In addition, it can be read as an attempt to connect beyond the humancentred, to arrive at a sense of shared transspecies (Kohn 7) being-in-the-world, allowing us to see that for "what it means to be human in all of its contingent complexity [...] we need to look to a context beyond the uniquely human" (6). We read Jack's desire for what is signified by the two men (significantly, he doesn't know if they are brothers or lovers-to some extent negating the need to know) and their dogs (Venter 238). It is in the transspecies square (2 men $\mathrm{x} 2$ dogs) that the relation whole of the Common surfaces, its immeasurable ability to be-all, to contain all affective being-in-the-world. This, to Jack, is something to be relished, the onto-aesthetic ferality of 'pure joy'.

Unfortunately, the Common episode coincides with Matt and Jack's progressively worsening terrorism against the Mkhonzas. Matt and Jack, however, see their hooliganism against the Mkhonzas not as a campaign of terror, but as a game; a game known to (Afrikaans) children as "Wolf, Wolf, hoe laat is dit?" (Wolf, wolf, what's the time?), with the temporal-symbolic echoes of the wording pointing towards a time of (perhaps, violent) reckoning, a time of endings. In the final chapters of the novel, Jack is killed after nearing the Mkhonzas' house whilst in the 'Wolfie' guise. This sense of a nearing end-activated by the echoing refrain of the game-points to larger questions of how we belong to national groupings and constantly-shifting cultural identifications; Matt and Jack's chosen homeless-ness, their wilful precarity, and their anti-social behaviour is understood as a rebellion against a perceived loss of power here seen in relation to the self's (in)ability to recode and adopt to new configurations of praxis. Their resemble-dog on the Common ultimately fail, and the novel's pervasive sense of loss comes full circle. 


\section{Conclusion}

The Common episode temporarily disrupts negative connotations with animals and makes resemble-dog productive, affirmative. Their renunciation of their dependency on power structures and renewed sense of (feral) connectivity brings about a new sense of relationality found in the 'companionable chaos. Venter's novel surfaces this, and other, zones of the undecidable between human and non-human animal. In this chapter, I read the presence of canid figures for how they activate Deleuzean shadows of shame, desire, and exclusion, which manifest in a set of behaviours and orientations towards others. In the novel, these states are metonymically represented by the father, Jack and Emile, but significantly activated by how we read the canid tropes of wolf, jackal, dog. Lest we forget, "masculinity does not exist as the property, character trait or aspect of identity of individuals" (MacInnes 2). In this sense, Matt's being is reflected, refracted, in the body of his father, the body of his lover, the body of the other. The novel charts this interplay between (sexual) connection and (social) exclusion, and we read this interplay onto/into the canid tropes.

These states of flux, of in-between-ness, are given shape in Venter's novel not merely in the presence of canid figures themselves, but rather in the zones of interaction activated by their presence, specifically in how they are read as figures of masculine inclusion and migrant exclusion, and the unbridled though temporary joy of the Common. Read together, these tropes pose larger questions on the effects of loss on categories of belonging. If we accept that the self is not static, then categories of (national, sexual, familial) belonging can be read as assemblages of processes, sensations, affects and ideas. Read in this way, the novel comments on the process of being South African-a process where being (what I am) and self (who I am) are performed in relation to larger, national assemblages of belonging, themselves in constant flux. Venter probes what it means to be, to act, not only as son and lover and migrant, but also as South African. The doubled "wolf" of the novel's title signifies two sides of being: doubled notions of natural and unnatural, of normative against subversive ways of being. Not so much 'wolf, wolf' as 'foreign dog, tame(d) wolf'.

\section{NOTES}

1. The English translation's response is a modulation of the Afrikaans original's "Je vous comprends"-a change which implies not only a formality shift, but also a potential shift from plural (or even collective) you/vous to singular you/te. 
On queerly reading canid tropes in Eben Venter's Wolf, Wolf

\section{WORKS CITED}

Beckman, F. Between Pleasure and Desire: A Deleuzean Theory of Sexuality. Edinburgh U P, 2014.

Deleuze, G. "Body, Meat, and Spirit: Becoming-Animal.” Francis Bacon: The Logic of Sensation. Trans. Daniel W. Smith. Bloomsbury Academic, 2003. pp. 19-24.

Gervasio, N. "Jack Halberstam's Queer Futures: Zombie Humanism at the end of the world." 2015. Columbia University in the City of New York, Institute for Research on Women, Gender and Sexuality. Blog. <http://irwgs.columbia.edu/blog/jack-halberstams-queer-futures-zombiehumanism=end-world.> Accessed 1 Dec. 2016.

Kohn, E. "How dogs dream: Amazonian natures and the politics of transspecies engagement." American Ethnologist vol. 34, no.1, pp. 3-24.

MacInnes, J. The End of Masculinity. Open U P, 1998.

Olson, G. Criminals as Animals from Shakespeare to Lombroso. Culture Machine Reviews, 2015.

Sedgwick, E. Between men: English literature and male homosocial desire. Columbia U P, 1985.

Venter, E. Wolf, Wolf. Tafelberg, 2013. 